\title{
Monitoring and characterizing natural hazards with satellite InSAR imagery
}

\author{
Zhong $\mathrm{Lu}^{\mathrm{a} *}$, Jixian Zhang ${ }^{\mathrm{b}}$, Yonghong Zhang ${ }^{\mathrm{b}}$ and Daniel Dzurisin ${ }^{\mathrm{a}}$ \\ ${ }^{a}$ US Geological Survey, Vancouver, WA, USA; ${ }^{b}$ Chinese Academy of Surveying and Mapping, Beijing, PR China
}

(Received 19 March 2009; final version received 4 February 2010)

\begin{abstract}
Interferometric synthetic aperture radar (InSAR) provides an all-weather imaging capability for measuring ground-surface deformation and inferring changes in land surface characteristics. InSAR enables scientists to monitor and characterize hazards posed by volcanic, seismic, and hydrogeologic processes, by landslides and wildfires, and by human activities such as mining and fluid extraction or injection. Measuring how a volcano's surface deforms before, during, and after eruptions provides essential information about magma dynamics and a basis for mitigating volcanic hazards. Measuring spatial and temporal patterns of surface deformation in seismically active regions is extraordinarily useful for understanding rupture dynamics and estimating seismic risks. Measuring how landslides develop and activate is a prerequisite to minimizing associated hazards. Mapping surface subsidence or uplift related to extraction or injection of fluids during exploitation of groundwater aquifers or petroleum reservoirs provides fundamental data on aquifer or reservoir properties and improves our ability to mitigate undesired consequences. Monitoring dynamic water-level changes in wetlands improves hydrological modeling predictions and the assessment of future flood impacts. In addition, InSAR imagery can provide near-real-time estimates of fire scar extents and fire severity for wildfire management and control. All-weather satellite radar imagery is critical for studying various natural processes and is playing an increasingly important role in understanding and forecasting natural hazards.
\end{abstract}

Keywords: radar; synthetic aperture radar; SAR; interferometric synthetic aperture radar; InSAR; deformation; natural hazards

\section{The InSAR technique and recent developments}

Interferometric synthetic aperture radar (InSAR) involves the use of two or more synthetic aperture radar (SAR) images of the same area to extract landscape topography and patterns of surface change, including ground deformation. A SAR system transmits electromagnetic waves at a wavelength that can range from a few millimeters to tens of centimeters. Because a SAR actively transmits and receives signals backscattered from the target area and because radar wavelengths are mostly unaffected by weather clouds, a SAR can operate effectively during day and night under all weather conditions. Using a SAR processing technique (Curlander and McDonough 1991), both the intensity and the phase of the radar signal backscattered from each ground resolution element (typically a few meters to tens of meters in size) can be calculated and combined to form a complex-valued SAR image that represents the radar reflectivity of the ground surface. The intensity (or strength) of the SAR image is determined primarily by the terrain slope, surface roughness, and dielectric constant, whereas the phase value of the SAR image is determined primarily by the apparent distance between the satellite antenna and the ground target. An interferogram can be produced by combining the phase components of two SAR images of the same area acquired from similar vantage points. An interferogram formed in this way depicts range changes between the radar and the ground resolution elements and can be used to derive both landscape topography and (if the SAR images are acquired at different times, see below) subtle changes in surface elevation (Massonnet and Feigl 1998, Lu et al. 2007a).

InSAR images are formed by combining or 'interfering' radar signals from two spatially or temporally separated antennas. The spatial separation between two antennas, or between two vantage points of the same antenna, is called the baseline. Two antennas can be mounted on a single platform for simultaneous interferometry. This is the usual implementation for airborne systems (e.g., Topographic SAR) and spaceborne systems (e.g., Shuttle Radar Topography Mission) for generating high-resolution, precise digital elevation models (DEMs) over large regions. Alternatively, InSAR images can be formed by using a single antenna on an airborne or spaceborne platform in nearly identical repeating flight lines or orbits for repeatpass interferometry (Massonnet and Feigl 1998, Lu et al. 2007a). In this case, even though successive observations of the target area are separated in time, the observations will be highly correlated if the backscattering properties of the surface have not changed in the interim. In this way, InSAR is capable of measuring ground-surface deformation with sub-

\footnotetext{
*Corresponding author. Email: lu@usgs.gov
} 
centimeter precision for C-band sensors $(\lambda=4-8 \mathrm{~cm})$ or few-centimeter precision for L-band sensors $(\lambda=15$ $30 \mathrm{~cm}$ ), in both cases at a spatial resolution of tens-ofmeters over a large region. This is the typical implementation for spaceborne sensors, including European Remotesensing Satellite 1 (ERS-1) (operated 1991-2000, C-band, wavelength $\lambda=5.66 \mathrm{~cm})$, Japanese Earth Resources Satellite 1 (JERS-1) $(1992-1998$, L-band, $\lambda=23.5 \mathrm{~cm})$, Shuttle Imaging Radar-C (April-October 1994; X-, C-, and L-band; $\lambda=3.1,5.66$, and $24.0 \mathrm{~cm}$, respectively), European Remote-sensing Satellite 2 (ERS-2) (1995-present, C-band, $\lambda=5.66 \mathrm{~cm}$ ), Canadian Radar Satellite 1 (Radarsat-1) (1995-present, C-band, $\lambda=5.66 \mathrm{~cm})$, European Environmental Satellite (Envisat) (2002-present, C-band, $\lambda=5.63 \mathrm{~cm}$ ), Japanese Advanced Land Observing Satellite (ALOS) (January 2006-present, L-band, $\lambda=23.6 \mathrm{~cm})$, Canadian RADARSAT-2 (2007present, C-band, $\lambda=5.55 \mathrm{~cm}$ ), German TerraSAR-X (2007-present, X-band, $\lambda=3.1 \mathrm{~cm}$ ), and the Italian COSMO-SkyMed satellite constellation (2007-present, Xband, $\lambda=3.1 \mathrm{~cm}$ ).

Two factors adversely affect repeat-pass InSAR measurement accuracy: atmospheric delay anomalies (Zebker et al. 1997) and loss of InSAR coherence (Zebker and Villasenor 1992). Differences in atmospheric temperature, pressure, and water-vapor content at two observation times can cause differing path delays and consequent anomalies in an InSAR deformation image. Atmospheric delay anomalies can reduce the accuracy of InSAR-derived deformation measurements from several millimeters under ideal conditions to a few centimeters under more typical conditions, thus obscuring subtle changes that can hold clues to the cause of the deformation. The effect of atmospheric delays can be lessened by routinely estimating water-vapor content using a high-resolution weather model, a continuous global positioning system network, or other satellite sensors such as the Moderate Resolution Imaging Spectroradiometer, Advanced Spaceborne Thermal Emission and Reflection Radiometer, and European Medium Resolution Imaging Spectrometer ( $\mathrm{Li}$ et al. 2003, Foster et al. 2006). In addition, multi-temporal InSAR images can be used to reduce artifacts due to atmospheric delay anomalies, orbit errors, DEM-induced artifacts, and loss of coherence. 'Multi-temporal' in this context refers to a series of InSAR observations that overlap in time, thus affording the opportunity to recognize spurious effects that do not correlate over time. Stacking and least squares inversion approaches, which could take into account covariance characteristics of a data distribution, can be applied to multitemporal InSAR images to reduce atmospheric delay anomalies and improve temporal sampling, which can help to reveal transient, dynamic deformation patterns (Berardino et al. 2002). A second factor that can adversely affect repeat-pass InSAR accuracy is loss of InSAR coherence (Zebker and Villasenor 1992). Changes in radar backscattering characteristics caused by environmental changes due to vegetation, snow, ice, and so on tend to lower the signal-to-noise ratio in InSAR measurements, sometimes resulting in complete loss of coherence in part or all of an interferogram. Such an image can be useful in some cases to map the spatial distribution of surface changes, but the interferometric information necessary to produce a DEM or measure surface deformation is lost. Factors that mitigate loss of InSAR coherence include a small spatial baseline, short temporal separation between observations, and longer radar wavelength.

Persistent Scatterer (PS) InSAR (PSInSAR) (Ferretti et al. 2001, Hooper et al. 2007) is one of the most significant recent advances in InSAR research. PSInSAR uses the distinctive backscattering characteristics of certain ground targets (persistent scatterers) and unique characteristics of atmospheric delay anomalies to improve the accuracy of conventional InSAR deformation measurements (Ferretti et al. 2001). The SAR backscattering signal of a PS target has a broadband spectrum in the frequency domain, implying that the radar phase of this kind of scatterer correlates over much longer time intervals and over much longer baselines than other scatterers. As a result, if the backscatter signal from a given pixel is dominated by return from one or more PS(s), the pixel remains coherent over long time intervals. Therefore, at PS pixels, the limitation imposed by loss of coherence in conventional InSAR analysis can be overcome. In addition, the atmospheric contribution is rather smooth spatially and is independent over time. Because InSAR coherence is maintained at PS pixels, the atmospheric contribution to the backscattered signal, the DEM error and orbit error can be identified and removed from the data using a multi-interferogram approach. After removing errors due to atmospheric anomalies, orbit error, and DEM error, deformation histories at PS points can be resolved with millimeter accuracy.

Another drawback of the current InSAR technique is sparse temporal sampling of InSAR images from spaceborne sensors. In many cases, documenting the transient behavior of deformation is critical for hazard-mitigation purposes. However, transient deformation can be short-lived, and many times it cannot be captured with InSAR due to long sensor-revisit times (e.g., 35 days for ERS and Envisat, 44 days for JERS-1, 24 days for Radarsat-1, and 46 days for ALOS). Shorter revisit times are possible with some of these sensors, though, by sacrificing resolution for timeliness. The SARs onboard Envisat, Radarsat-1, and ALOS are capable of acquiring images in both strip and scan modes. In strip mode, radar-antenna pointing (look angle) is fixed along the flight path and the antenna footprint covers a relatively narrow strip (swath) on the surface to one side of the orbit track $(\sim 100 \mathrm{~km}$ wide in the cross-track direction). Currently, strip-mode SAR images are used for most InSAR deformation mapping applications. Scan-mode SAR (ScanSAR) is achieved by periodically increasing the antenna look angle to illuminate neighboring sub-swaths in the cross-track direction, thereby increasing the size of the accessible image swath to 400$500 \mathrm{~km}$. Because ScanSAR can acquire more frequent 
observations of a given study area than is possible with stripmode SAR (albeit at somewhat lower spatial resolution), interferometric ScanSAR can significantly improve the temporal resolution of deformation mapping (Guarnieri and Rocca 1999). For example, at a the latitude of $45^{\circ}$, Envisat can acquire 15 ScanSAR images in 35 days while it can only obtain about four strip-mode SAR images. Therefore, repeat times as short as 3 days can be achieved with Envisat images acquired in ScanSAR mode. This makes ScanSAR InSAR a very attractive tool for monitoring transient deformation signals, including those commonly associated with volcanic unrest and postseismic responses to major earthquakes.

Most spaceborne SARs such as those onboard ERS-1, ERS-2, JERS-1, and Radarsat-1 are single-polarized radars (i.e., radar signals are transmitted with vertical or horizontal polarization and received with vertical or horizontal polarization, respectively). Therefore, the return signal from these sensors only partially captures the scattering properties of targets on the surface. Images from a fully polarized radar (i.e., radar signals are transmitted and received with both vertical and horizontal polarizations), such as those onboard the Japanese ALOS satellite and future radar satellites, can be related to the signatures of known elemental targets, making it possible to infer the type of scattering that is taking place (Touzi et al. 2004). Polarization signatures of the vegetation canopy, lower vegetation, and the ground are different and can be separated using polarimetric analysis. An optimization procedure can be employed to maximize the interferometric coherence between two polarimetric radar images to reduce the effect of baseline and temporal decorrelation on the interferogram. Then, using a coherent target decomposition approach that separates distinctive backscattering returns from the canopy top, the bulk volume of the forest, and the ground surface, one can derive the difference of interferometric phase measurements that leads to the height differences between physical scatterers with differing scattering characteristics (Cloude and Papathanassiou 1998). Physical radar backscattering models for different vegetation types can be developed to calculate the canopy height, the bare-earth topography, the mean volume extinction coefficient that is related to canopy density, and other canopy structural parameters based on measurements from a polarimetric InSAR image. By analyzing multiple polarimetric InSAR images, researchers will be able to monitor vegetation changes caused by wildfires, volcanic eruptions, and other natural processes.

\section{Natural hazards monitoring and characterization with InSAR}

\subsection{Earthquakes}

InSAR was first used to map ground surface displacements caused by the 1992 M7.3 Landers earthquake (Massonnet et al. 1993). Using a pair of SAR images, one acquired before the earthquake and the other after the earthquake, InSAR can be used to map the co-seismic deformation field and in turn to estimate earthquake location, fault geometry, and rupture dynamics (Figure 1a and b) (Lu et al 2003b). Multipletemporal InSAR images can be used to estimate interseismic strain accumulation, which is crucial to understanding continental deformation, the earthquake cycle, and seismic hazards (Biggs et al. 2007). InSAR can map ground surface deformation immediately after an earthquake (i.e., post-seismic deformation), which yields important information for inferring properties of Earth's crust and upper mantle (Figure 1c) (Biggs et al. 2009). InSAR is playing an increasingly important role in mapping triggered slip, which occurs during an earthquake on faults not involved in the main shock and therefore is extremely difficult to capture with conventional geodetic techniques (Fialko et al. 2002). In addition, InSAR can identify blind faults (i.e., buried faults that do not intersect the ground surface) from surface deformation patterns. Combined with seismology and other geophysical and geodetic techniques, InSAR can be expected to foster many breakthroughs in understanding the physics of the earthquake cycle (Wright 2002).

\subsection{Volcanoes}

SAR data acquired before and after a volcanic eruption can be used to image co-eruptive deformation and can provide essential information about magma dynamics (Dzurisin 2003, 2007, Lu 2007, Lu et al. 2007b). In addition, InSAR can be used to map volcano deformation during otherwise quiescent periods and to map the distribution of volcanic deposits and calculate their thickness and volume (see below). InSAR-derived surface deformation patterns can provide important insight into the structure, plumbing, and state of restless volcanoes and can be the first sign of increasing unrest that might include earthquake swarms or other precursors to an impending intrusion or eruption. For example, Lu et al. (2007b) used InSAR images from ERS-1, ERS2, JERS-1, Radarsat-1, and Envisat to study ground surface deformation associated with a variety of volcanic processes at Aleutian volcanoes (Figure 2), including (1) volcanic inflation and magma intrusion, (2) deformation preceding seismic swarms at several active and quiescent volcanoes, (3) persistent volcano-wide subsidence at calderas that last erupted hundreds of years ago, (4) magma intrusion and associated tectonic stress release at active volcanoes, (5) subsidence caused by a decrease in pore fluid pressure in active hydrothermal systems, and (6) lack of expected deformation associated with recent eruptions at frequently active volcanoes (Kwoun et al. $2006 \mathrm{Lu}$ et al. 1998, 2000a, 2000b, 2000c, 2002a, 2002b, 2002c, 2003a, 2003c, 2003d, 2005a, 2005b, 2007b, Masterlark and Lu 2004). The dense spatial distribution of surface deformation data derived from InSAR images enables the construction of detailed numerical models that can further understanding of magmatic processes. Systematic mapping of deformation along volcanic arcs can provide a basis for improved modeling and better understanding of magmatic plumbing systems in subduction zone settings. 

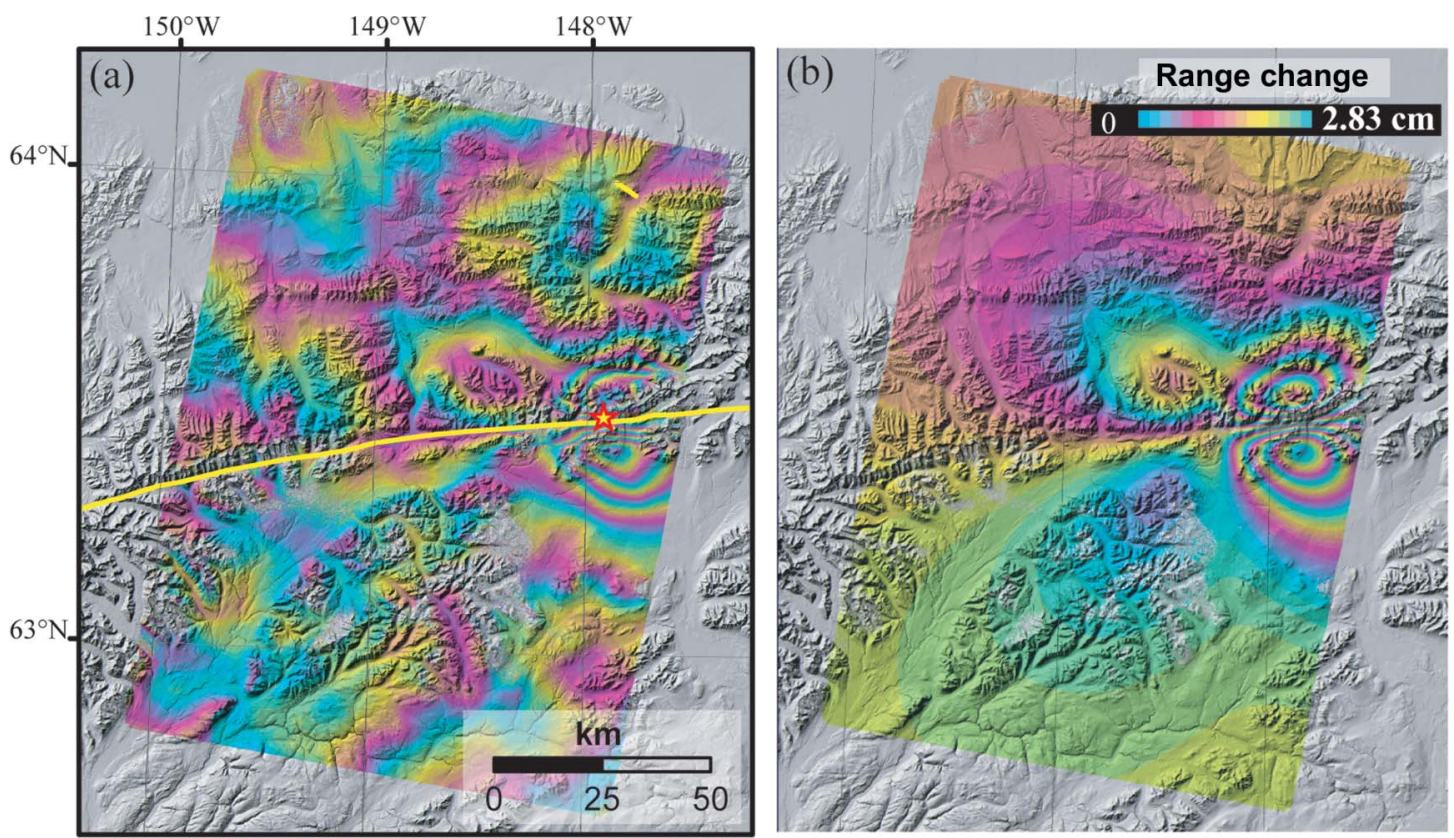

(c)
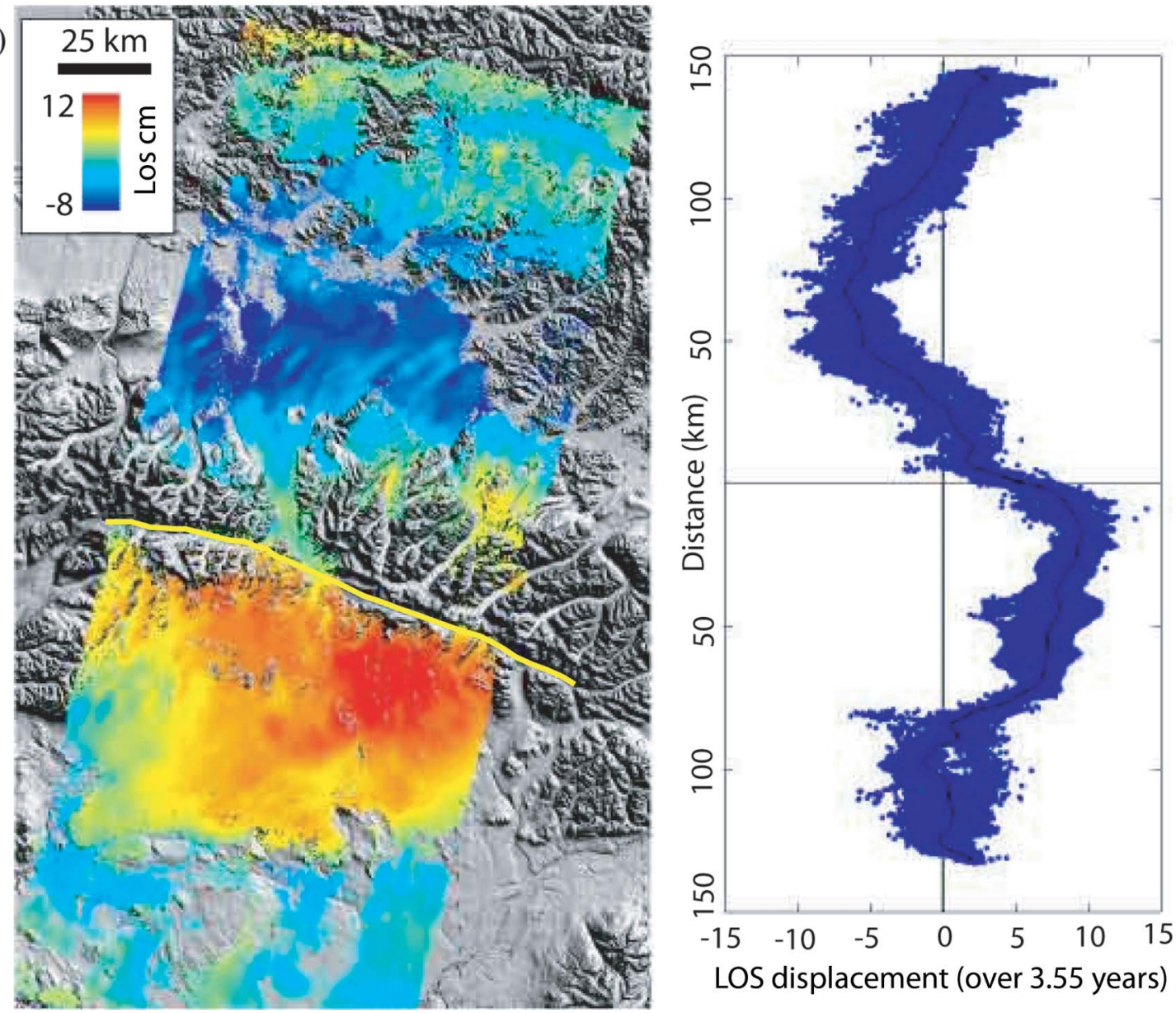

Figure 1. (a) Radarsat-1 InSAR image (16 August-27 October 2002) showing coseismic ground surface deformation associated with the 23 October 2002, M6.7 Nenana Mountain earthquake along the Denali Fault, Alaska, which preceded the M7.9 Denali earthquake by about 10 days. Solid line marks fault trace. (b) Modeled InSAR image using fault parameters that best fit the observed interferogram shown in (a). (c) Post-seismic deformation image and line-of-sight displacement profile showing ground response during 2003-2004 to the 3 November 2002, M7.9 Denali Fault earthquake. The image is a stack of four Radarsat-1 interferograms. Peak deformation is at a distance of $\sim 60 \mathrm{~km}$ from the fault trace (solid yellow line) and is consistent with GPS models of viscoelastic relaxation below $60 \mathrm{~km}$ depth. 


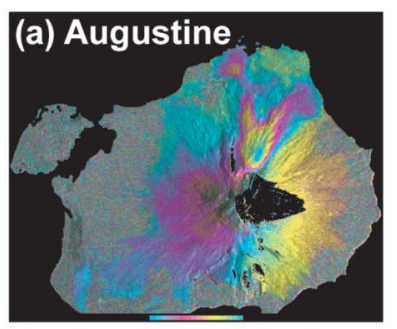

\section{(b) Peulik}

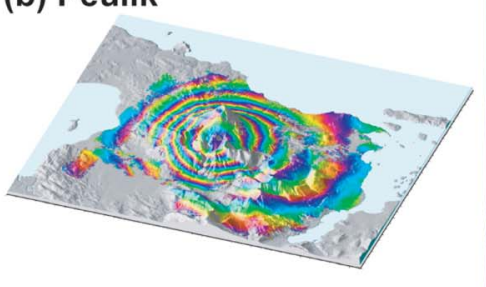

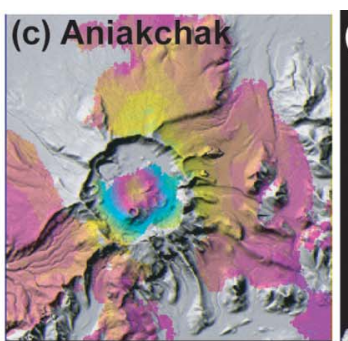

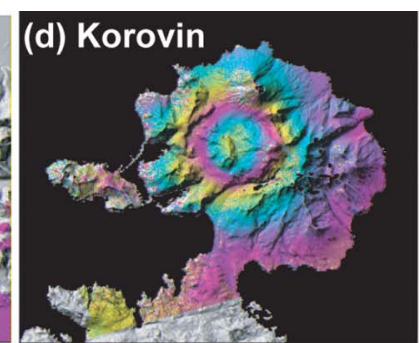

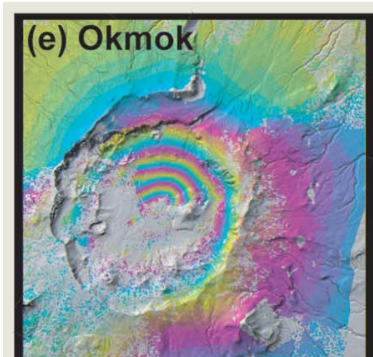

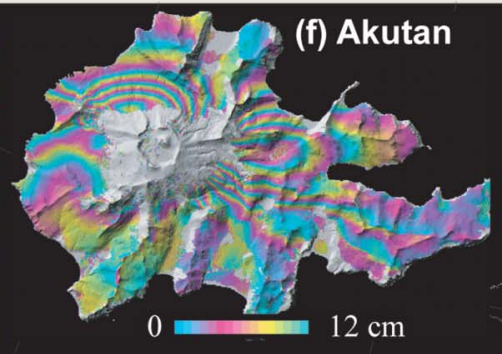

\section{-}

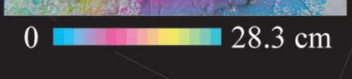

$0 \stackrel{\mathrm{cm}}{\longrightarrow} 12 \mathrm{c}$
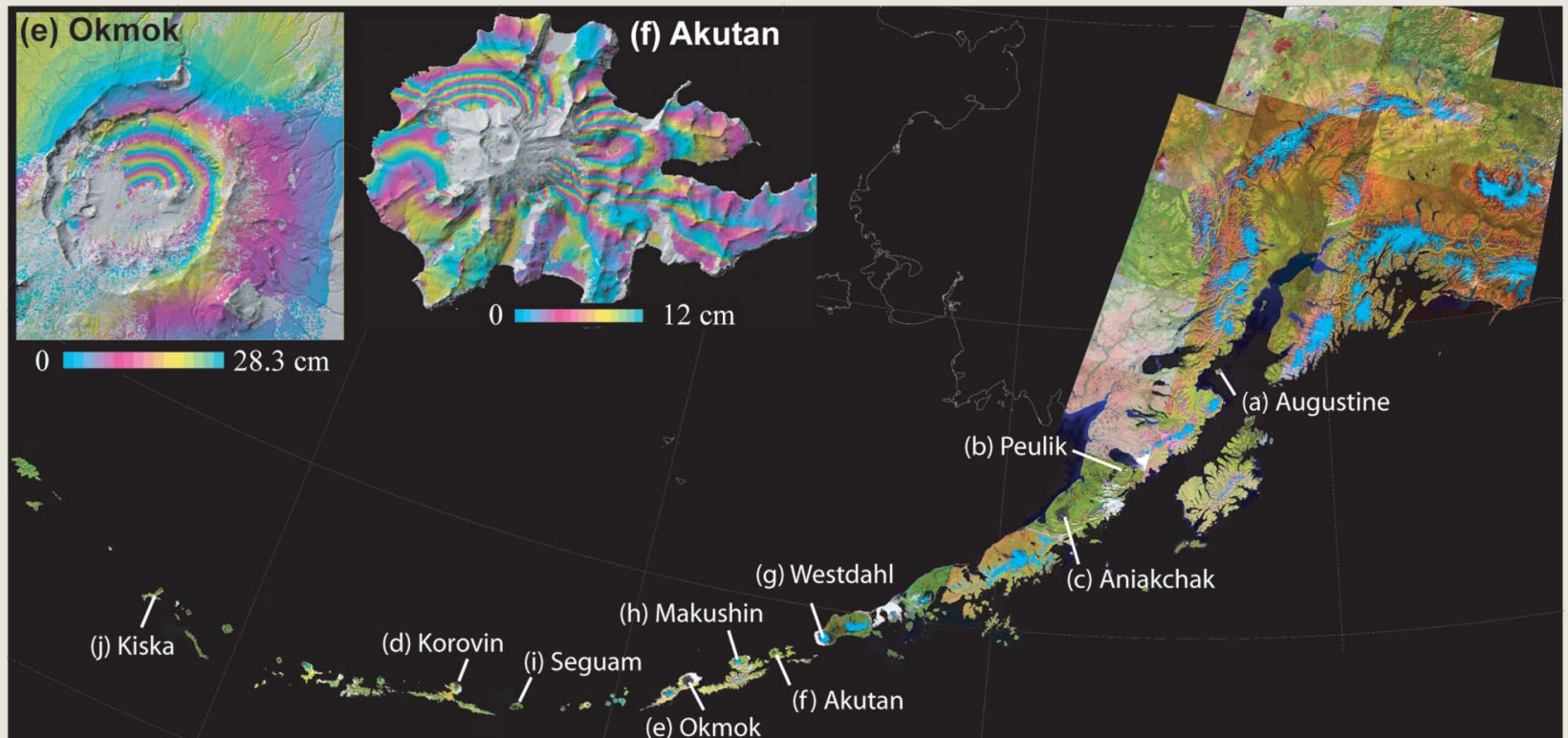

(e) Okmok

\section{(g) Westdahl}

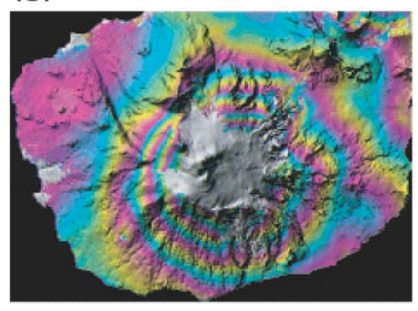

(h) Makushin

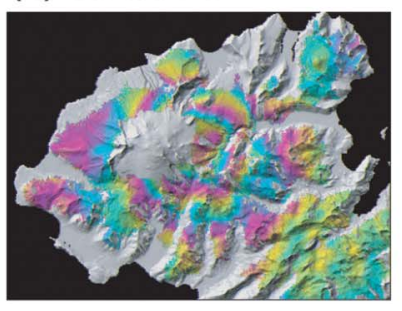

(i) Seguam

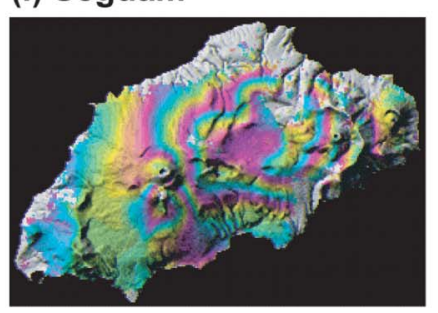

(j) Kiska

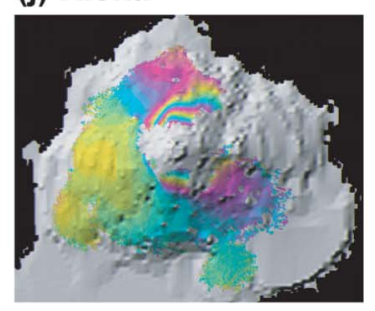

Figure 2. InSAR deformation images of selected volcanoes in the Aleutian Islands. (a) Augustine Volcano, showing deformation during 1992-1993 caused by compaction of 1986 pyroclastic flow deposits. (b) Peulik Volcano, showing as much as $\sim 17 \mathrm{~cm}$ of uplift during 1996-1997. (c) Aniakchak Volcano, showing that the caldera subsided $\sim 13 \mathrm{~mm} /$ year during 1992-2002 (averaged image). (d) Korovin Volcano, showing more than $4 \mathrm{~cm}$ of inflation associated with elevated seismicity from July to September 2006. (e) Okmok Volcano, showing deflation of $\sim 1.2 \mathrm{~m}$ associated with the 1997 eruption there. (f) Akutan Volcano, showing the complex deformation field that accompanied an intense earthquake swarm in March 1996 (L-band JERS-1 InSAR image). (g) Westdahl Volcano, showing inflation that occurred aseismically during 1993-1998. (h) Makushin Volcano, showing $\sim 7 \mathrm{~cm}$ of surface uplift associated with a small explosive eruption in January 1995. (i) Seguam Volcano, showing surface uplift of more than $6 \mathrm{~cm}$ during 1999-2000. (j) Kiska Volcano, showing subsidence due to an inferred change in the hydrothermal system during 1999-2000. All interferograms are draped over DEM-shaded relief images. Areas without interferometric coherence are uncolored. The Landsat-7 image mosaic was provided by S. Smith of the Alaska Volcano Observatory.

\subsection{Land surface deformation associated with fluid withdrawal}

Surface subsidence and uplift related to the extraction or injection of fluids in groundwater aquifers and petroleum reservoirs can be mapped by InSAR (Figure 3a). InSARbased surface deformation mapping can provide fundamental data on reservoir/aquifer properties and processes and improve the ability to assess and mitigate adverse consequences of fluid withdrawal or injection ( $\mathrm{Lu}$ and Danskin 2001). InSAR also can be used to map movement of slow-moving landslides, providing a new tool for monitoring this widespread natural hazard (Figure 3b). 

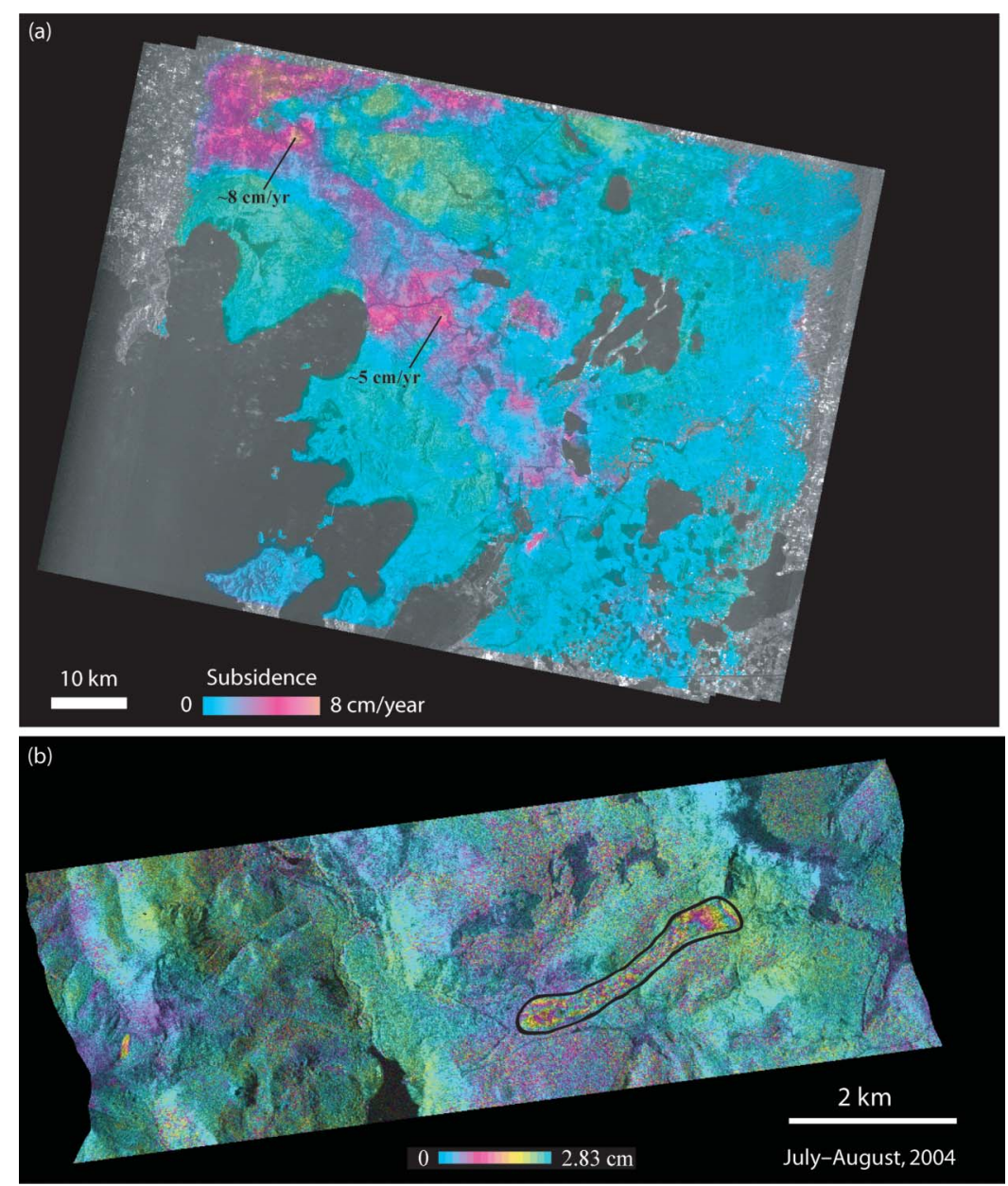

Figure 3. (a) Average deformation of Suzhou in southeastern China from L-band JERS-1 InSAR imagery. Subsidence of more than $10 \mathrm{~cm} /$ year during 1992-1996 is revealed by the multi-temporal InSAR images. (b) Movement of the Slumgullion landslide, Colorado, USA, mapped from a fine-beam Radarsat-1 image. Maximum displacement was more than $10 \mathrm{~cm}$ in 24 days during July-August 2004.

\subsection{Glaciers and ice fields}

InSAR has been used to record the movement of glaciers and ice fields and has significantly advanced the study of glacier, ice-flow, and ice-sheet mass balance (Figure 4). By regularly imaging ice sheets in the Arctic, Antarctica, and Greenland, InSAR has contributed to better documentation of the short-term evolution of ice sheets, thus improving understanding of their impact on sea-level change and global warming (Rignot and Thomas 2002).

\subsection{Water-level changes in wetlands}

Both L-band and C-band InSAR imagery can be used to measure water-level changes in river valleys and wetlands (Alsdorf et al. 2000, Lu et al. 2005c). InSAR images suggest that water-level changes in wetlands can be dynamic and spatially heterogeneous and might not be represented by readings from sparsely distributed gauge stations (Figure 5). Calibrated by in situ measurements, InSAR- derived water-level changes within wetlands allow precise estimation of volumetric changes in water storage, which can improve hydrological modeling predictions and assessments of future flood events (Lu and Kwoun 2008).

\subsection{Flooding}

SAR backscatter signal strength is controlled by environmental factors such as terrain slope, surface roughness (with respect to the wavelength of the sensor), and surface moisture content. Four primary types of SAR interactions that occur when a SAR signal impinges on Earth's surface are specular reflection (forward scattering), surface backscattering, volume backscattering, and double bounce backscattering (Lu and Kwoun 2008). Both specular and double bounce interactions can be useful for delineating the extent of flooding. During calm weather, water acts as a specular reflector for an incident SAR signal, resulting in very low backscatter returns that can be used to map flooded areas. If, 


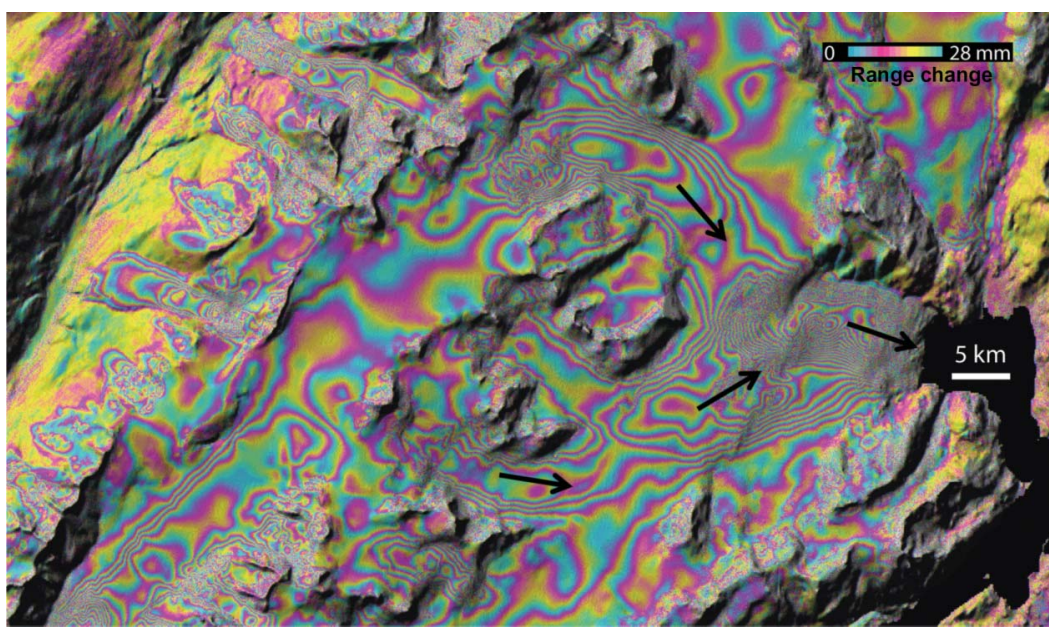

Figure 4. Movement of glaciers over Kenai Pennisula, southern Alaska in 24 hours between 12 and 13 November 1995. The interferometric phase image is draped over the radar intensity image. Each fringe (full-color cycle) represents a 2.8-cm change in range distance.
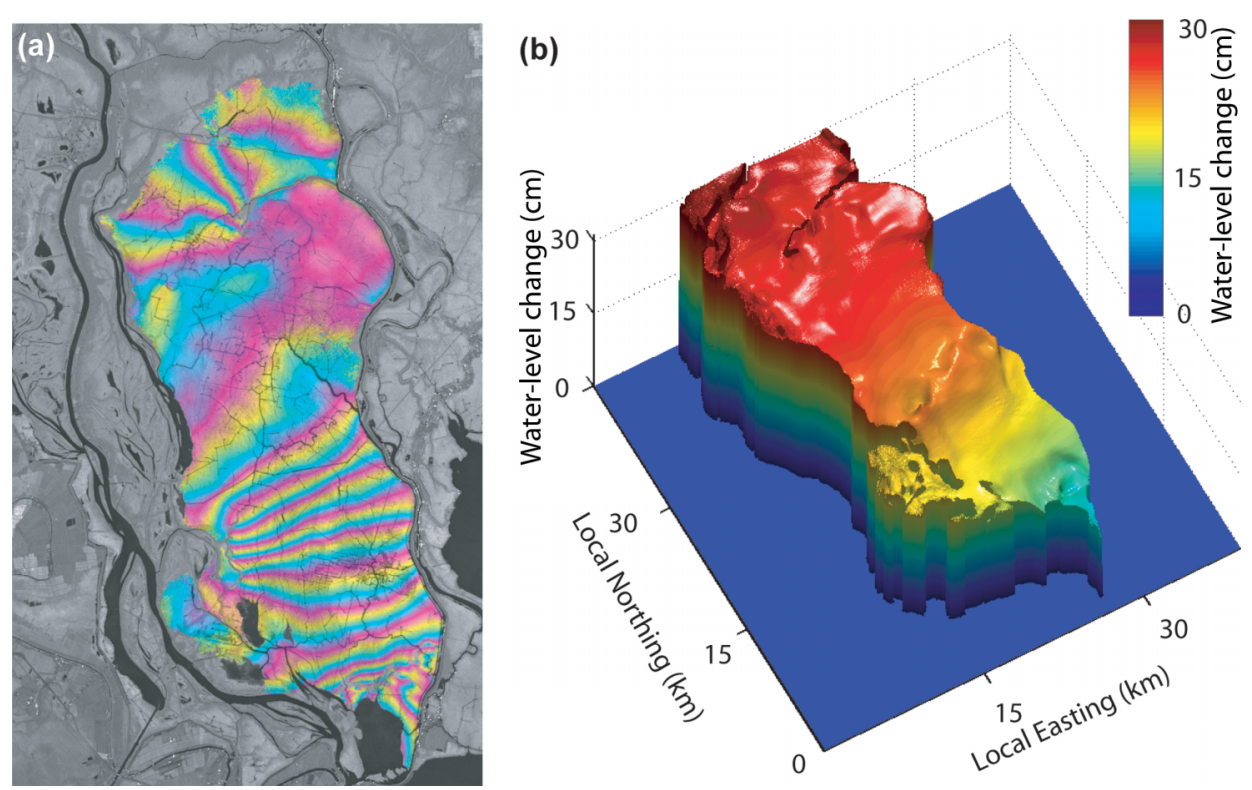

Figure 5. (a) C-band $(\lambda=5.7 \mathrm{~cm})$ interferogram produced from Radarsat-1 images, showing heterogeneous water-level changes in swamp forests in coastal Louisiana between 22 May and 15 June 2003. The interferometric phase image is draped over the radar intensity image. Each fringe (full-color cycle) represents a $2.8 \mathrm{~cm}$ change in range distance or a $3.1 \mathrm{~cm}$ change in water level. (b) A three-dimensional view of water-level changes derived from the InSAR image.

however, flooding occurs in areas with vegetation, a phenomenon known as a 'double bounce' interaction may occur. In a double bounce interaction, the SAR signal initially is reflected away from the sensor by the water's surface, toward a tree bole or other vertical structure, and then is reflected a second time back toward the sensor. The double bounce interaction results in a higher backscatter return than when the land surface is not flooded and therefore is important for identifying flooding in forested and urban areas (Figure 6). Discrimination between types of SAR interactions requires information relating to land cover conditions, which can be derived from a pre-event optical (e.g., Landsat) image (Rykhus and Lu 2007).

\subsection{DEMs}

InSAR can be used to construct DEMs of areas where the photogrammetric approach to DEM generation is hindered by persistent clouds or other factors. For example, repeat-pass InSAR can be used to calculate ice surface topography, which 


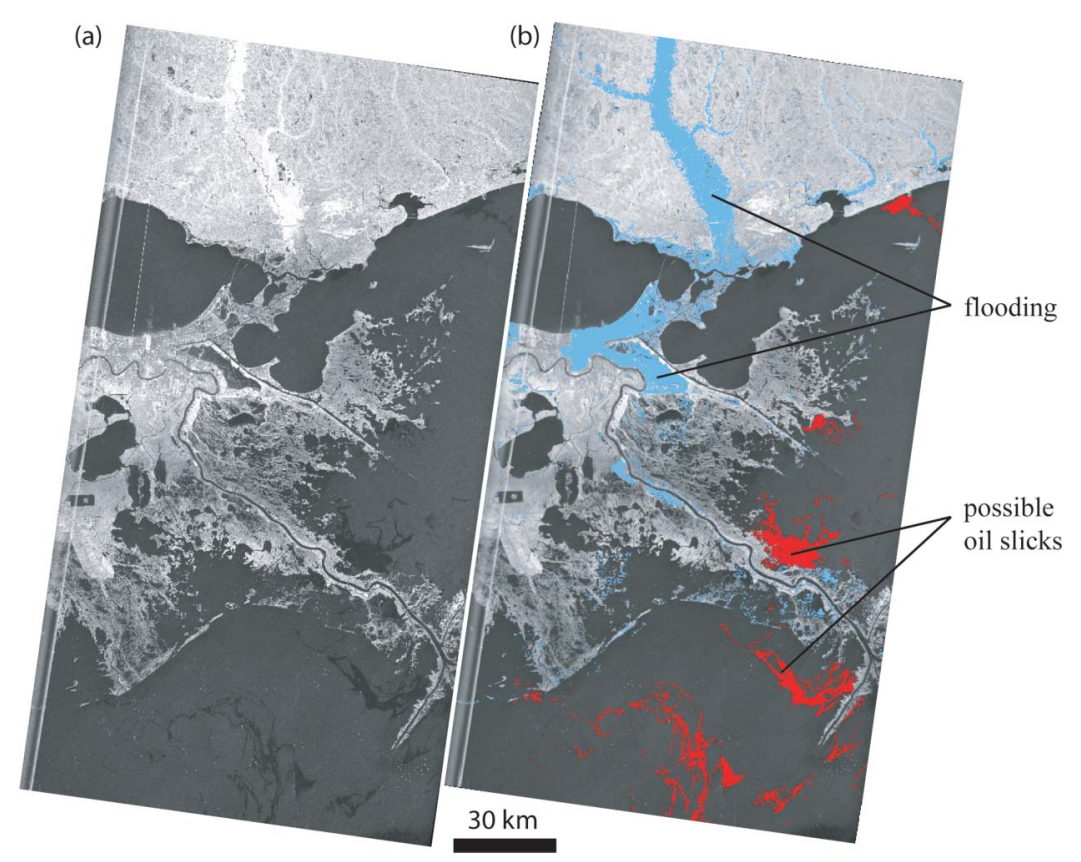

Figure 6. (a) Radarsat-1 image acquired on 2 September 2005, over New Orleans, Louisiana, USA. (b) The extent of flooding, mapped by combining the Radarsat-1 image with a pre-flood Landsat Enhanced Thematic Mapper Plus (ETM+) image mosaic. Several possible oil slicks are identified. Calm water acts as a specular reflector (or forward scatterer) of the SAR signal, resulting in very low backscatter values for flooded areas. However, flooding in areas with tall vegetation or buildings can result in very high, 'double-bounce' backscattering, a phenomenon that is important for identifying flooding in forests and urban areas. The tendency of oil slicks on water is to dampen the roughness of the water, which allows for discrimination of slicks in open water under moderate to light wind conditions.

determines the magnitude and direction of the gravitational force that drives ice flow and ice dynamics. In addition, volcano surface topography measurements made before and after an eruption can be used to estimate the thickness and volume of lava flows or ash deposits (Figure 7). There are many sources of error in DEM construction from repeat-pass
InSAR images, for example, inaccurate determination of the InSAR baseline, atmospheric delay anomalies, possible surface deformation due to tectonic, volcanic, or other loading sources during the time interval spanned by the images. To generate a high-quality DEM from repeat-pass InSAR images, these errors must be identified and corrected (Lu et al. 2003c).
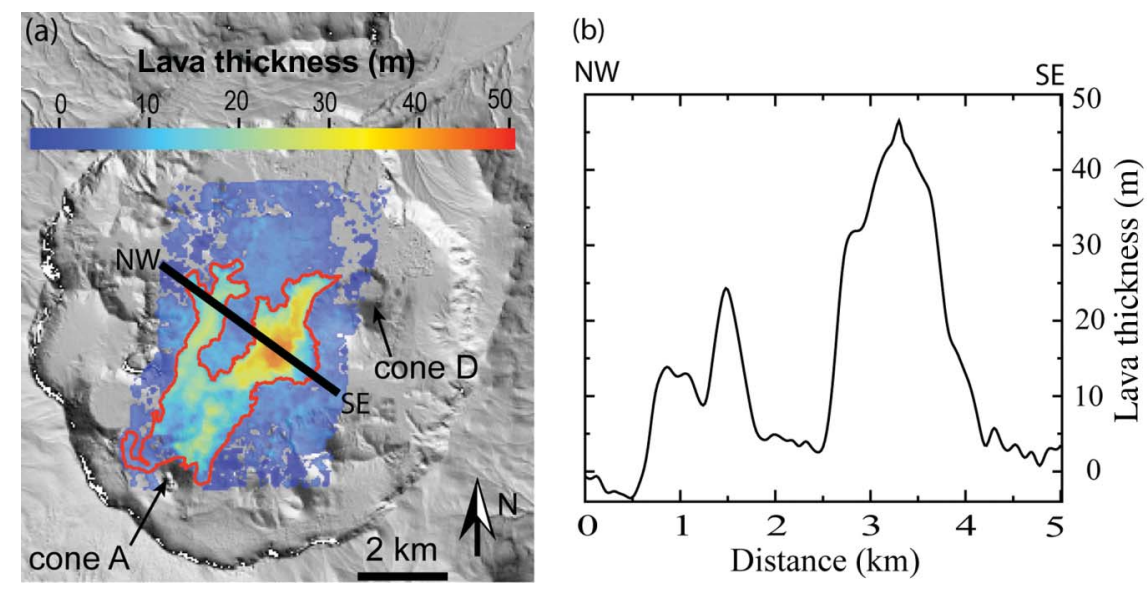

Figure 7. Thickness of lava flows emplaced during the April 1997 eruption at Okmok Volcano, Alaska. Flow thickness was derived from the height difference between pre-eruption and post-eruption DEMs that were constructed from repeat-pass InSAR images. (b) Lava thickness along profile S-S which reached nearly $50 \mathrm{~m}$ in the thickest part of the flow. 


\subsection{Land cover and changes}

InSAR images and their associated products (e.g., SAR intensity images and InSAR coherence image) have proven useful for mapping land cover types (Ramsey et al. 2006, Kwoun and Lu 2009) (Figure 8), land cover changes (Ramsey et al. 2009), and soil moisture changes (Lu and Meyer 2002). For example, multiple SAR images can be used to map the progression of fire and to estimate fire severity (Figure 9). InSAR products that characterize changes in SAR backscattering return (both intensity and phase) are indispensable for precise mapping of fire scar extents and severities. Future SAR sensors will be fully polarimetric, enabling advances in many fields including (1) land cover mapping and wetland mapping, particularly in regions where weather conditions hinder optical remote sensing; (2) improved understanding of the three-dimensional structure of terrestrial vegetation and its influence on habitat, agricultural and timber resources, fire behavior, and economic value; (3) mapping soil moisture at a resolution of several meters that is not attainable otherwise; and (4) characterizing the contributions of groundwater, surface water, soil moisture, and snow pack to the global fresh water budget.
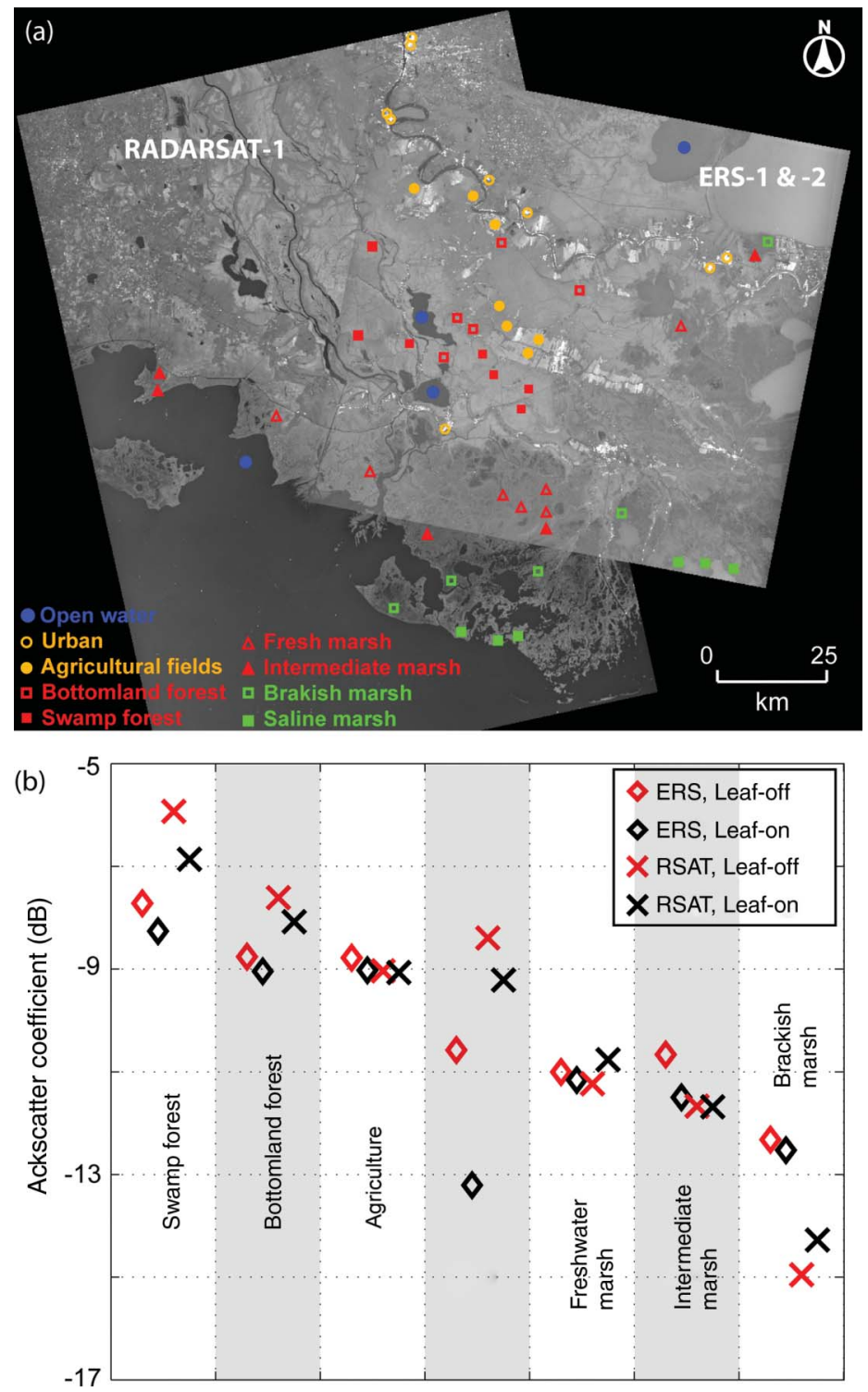

Figure 8. Averaged ERS-1/ERS-2 and Radarsat-1 intensity images of southeastern Louisiana, USA, with distinct land cover classes identified by symbols (explanation in lower left). (b) Averaged radar backscattering coefficients (relative to urban backscattering returns) for seven major land cover classes during both leaf-on and leaf-off seasons. Variations of the radar-backscattering coefficient were used to distinguish different land cover types. 

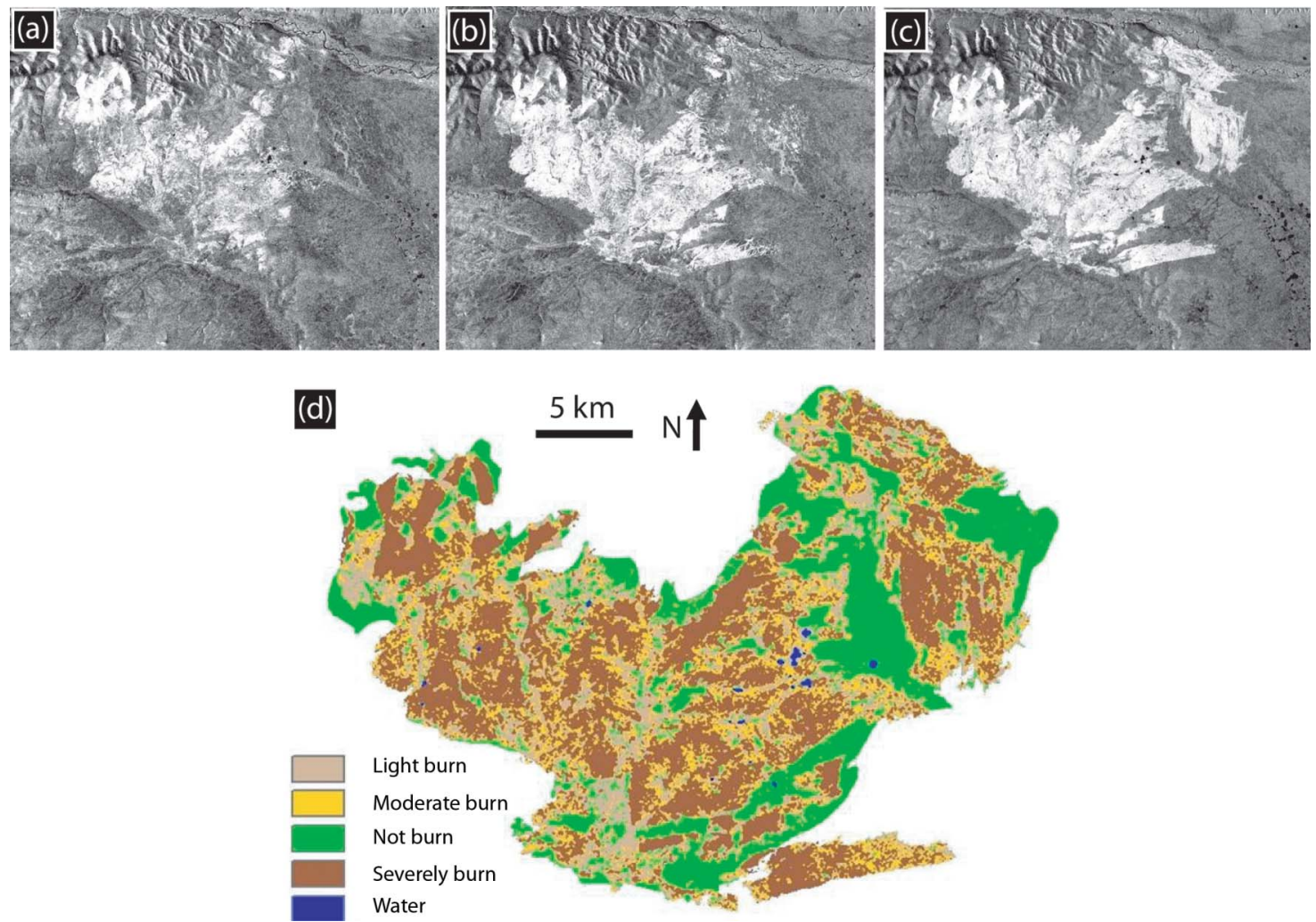

Figure 9. Radarsat-1 SAR intensity images of the Yukon River Basin, Alaska, acquired on (a) 17 August 2003, (b) 10 September 2003, and (c) 4 October 2003. These SAR images show the progression of a fire that started in July 2003 (successively larger bright areas). The derived fire severity map is shown in (d).

\section{Concluding remarks}

InSAR is one of the fastest growing fields in Earth science and remote sensing. InSAR observations of precise land surface topography and time-transient surface variability will accelerate development of predictive models that can anticipate the behavior of many natural hazards such as volcanic eruptions, earthquakes, landslides, and wild fires. In addition, InSAR will provide tools to better characterize the role of glaciers and ice sheets in sea-level rise and global warming, and the contributions of groundwater, surface water, soil moisture, and snow to the global fresh water budget. Furthermore, InSAR will offer the capability of imaging the three-dimensional structure of vegetation on a global scale for improved characterization and management of Earth's resources.

To monitor landscape change and ground surface deformation associated with natural hazards on an operational basis, a SAR/InSAR processing system is needed to automatically process and manage large amounts of SAR data. The system should be capable of cataloging, archiving, and retrieving processed InSAR images and associated products through a Web-based graphical user interface. An automated InSAR processing system and associated graphical user interface could be the foundation for real-time analysis of InSAR images to monitor ground surface deformation and other surface changes. Because more satellite radar sensors and constellations of radar satellites will become available in the next decade, an automated SAR/InSAR processing system for hazard monitoring is of paramount importance for near-real-time decision support.

With more and more operational SAR sensors available for timely data acquisitions, InSAR - coupled with state-ofthe-art information technologies such as data-mining and grid computation - will continue to address and provide solutions to many scientific questions related to natural hazards monitoring and characterization.

\section{Acknowledgements}

ERS-1/-2 and Envisat, Radarsat-1 and JERS-1 SAR images are copyrighted by European Space Agency, Canadian Space Agency, and Japan Aerospace Exploration Agency, respectively, and were provided by the Alaska Satellite Facility and European Space Agency. This work was supported by funding from the NASA Earth Surface \& Interior Program, USGS Land Remote Sensing Program, and USGS Volcano Hazards Program. Technical reviews by Ohig Kwoun and Russ Rykhus are greatly appreciated. The paper benefited from discussions with many colleagues, particularly Ohig Kwoun, Russ Rykhus, Chuck Wicks, Juliet Biggs, and Tim Wright. 


\section{References}

Alsdorf, D., et al., 2000. Interferometric radar measurements of water level changes on the Amazon floodplain. Nature, 404, 174-177.

Berardino, P., et al., 2002. A new algorithm for surface deformation monitoring based on small baseline differential SAR interferograms. IEEE Transactions on Geoscience and Remote Sensing, 40, 2375-2383.

Biggs, J., et al., 2007. Multi-interferogram method for measuring interseismic deformation: Denali Fault, Alaska. Geophysical Journal International, 173, 1165-1179.

Biggs, J., et al., 2009. The postseismic response to the 2002 M7.9 Denali Fault earthquake: constraints from InSAR. Geophysical Journal International, 176, 353-367.

Cloude, S. and Papathanassiou, K., 1998. Polarimetric SAR interferometry. IEEE Transactions on Geoscience and Remote Sensing, 36, 1551-1565.

Curlander, J. and McDonough, R., 1991. Synthetic aperture radar systems and signal processing. New York: John Wiley \& Sons.

Dzurisin, D., 2003. A comprehensive approach to monitoring volcano deformation as a window on eruption cycle. Review of Geophysics, 41, Doi: 10.1029/2001RG000107.

Dzurisin, D., 2007. Volcano deformation - geodetic monitoring techniques. Chichester, UK: Springer-Praxis Publishing Ltd.

Ferretti, A., Prati, C., and Rocca, F., 2001. Permanent scatterers in SAR interferometry. IEEE Transactions on Geoscience and Remote Sensing, 39, 8-20.

Fialko, Y., et al., 2002. Deformation on nearby faults induced by the 1999 Hector Mine earthquake. Science, 297, 1858-1862.

Foster, J., et al., 2006. Mitigating atmospheric noise for InSAR using a high-resolution weather model. Geophysical Research Letters, 33, L16304, Doi: 10.1029/2006GL026781.

Guarnieri, A.M. and Rocca, F., 1999. Combination of low- and high-resolution SAR images for differential interferometry. IEEE Transactions on Geoscience and Remote Sensing, 37, 2035-2049.

Hooper, A., Segall, P., and Zebker, H., 2007. Persistent scatterer interferometric synthetic aperture radar for crustal deformation analysis, with application to Volcán Alcedo, Galápagos. Journal of Geophysical Research, 112, B07407, Doi: 10.1029/2006JB004763.

Kwoun, O., et al., 2006. Quiescent deformation of the Aniakchak Caldera, Alaska, mapped by InSAR. Geology, 34, 5-8.

Kwoun, O. and Lu, Z., 2009. Multi-temporal RADARSAT-1 and ERS backscattering signatures of coastal wetlands at Southeastern Louisiana. Photogrammetric Engineering \& Remote Sensing, 75 (5), 607-617.

Li, Z., Muller, J.P., and Cross, P., 2003. Comparison of precipitable water vapor derived from radiosonde, GPS, and moderateresolution imaging spectroradiometer measurements. Journal of Geophysical Research, 108 (D20), 4651, Doi: 10.1029/ 2003JD003372.

Lu, Z., 2007. InSAR imaging of volcanic deformation over cloudprone areas - Aleutian Islands. Photogrammetric Engineering \& Remote Sensing, 73, 245-257.

Lu, Z. and Danskin, W., 2001. InSAR analysis of natural recharge to define structure of a ground-water basin, San Bernardino, California. Geophysical Research Letters, 28, 2661-2664.

Lu, Z. and Kwoun, O., 2008. Radarsat-1 and ERS interferometric analysis over southeastern coastal Louisiana: implication for mapping water-level changes beneath swamp forests. IEEE Transactions on Geoscience and Remote Sensing, 46, 2167-2184.

Lu, Z., Mann, D., and Freymueller, J., 1998. Satellite radar interferometry measures deformation at Okmok volcano. Eos,
Transactions of the American Geophysical Union, 79, 461468.

Lu, Z. and Meyer, D., 2002. Study of high SAR backscattering due to an increase of soil moisture over less vegetated area: its implication for characteristic of backscattering. International Journal of Remote Sensing, 23, 1065-1076.

Lu, Z., et al., 2000a. Ground deformation associated with the March 1996 earthquake swarm at Akutan volcano, Alaska, revealed by satellite radar interferometry. Journal of Geophysical Research, 105, 21483-21496.

Lu, Z., et al., 2000b. Aseismic inflation of Westdahl volcano, Alaska, revealed by satellite radar interferometry. Geophysical Research Letters, 27, 1567-1570.

Lu, Z., et al., 2000c. Synthetic aperture radar interferometry of Okmok volcano, Alaska: radar observations. Journal of Geophysical Research, 105, 10791-10806.

Lu, Z., et al., 2002a. Subsidence at Kiska volcano, Western Aleutians, detected by satellite radar interferometry. Geophysical Research Letters, 29, 1855, Doi: 10.1029/2002GL014948.

Lu, Z., et al., 2002b. Magmatic Inflation at a Dormant Stratovolcano: 1996-98 activity at Mount Peulik Volcano, Alaska, revealed by satellite radar interferometry. Journal of Geophysical Research, 107, 2134, Doi: 10.1029/ 2001JB000471.

Lu, Z., et al., 2002c. Pre-eruptive inflation and surface interferometric coherence characteristics revealed by satellite radar interferometry at Makushin Volcano, Alaska: 1993-2000. Journal of Geophysical Research, 107, 2266, Doi: 10.1029/ 2001JB000970.

Lu, Z., et al., 2003a. Interferometric synthetic aperture radar studies of Alaska volcanoes. Earth Observation Magazine (EOM), 12, 8-18.

Lu, Z., Wright, T., and Wicks, C., 2003b. Deformation of the 2002 Denali Fault earthquakes, Alaska, mapped by Radarsat-1 interferometry. Eos, Transactions of the American Geophysical Union, 84, 425-431.

Lu, Z., et al., 2003c. Estimating lava volume by precision combination of multiple baseline spaceborne and airborne interferometric synthetic aperture radar: the 1997 eruption of Okmok volcano, Alaska. IEEE Transactions on Geoscience and Remote Sensing, 41, 1428-1436.

Lu, Z., et al., 2003d. Magma supply dynamics at Westdahl Volcano, Alaska, modeled from satellite radar interferometry. Journal of Geophysical Research, 108, Doi: 10.1029/ 2002JB002311.

Lu, Z., Masterlark, T., and Dzurisin, D., 2005a. Interferometric synthetic aperture radar (InSAR) study of Okmok Volcano, Alaska, 1992-2003: magma supply dynamics and postemplacement lava flow deformation. Journal of Geophysical Research, 110, B02403, Doi: 10.1029/2004JB003148.

Lu, Z., et al., 2005b. Surface deformation associated with the March 1996 earthquake swarm at Akutan Island, Alaska, revealed by C-band ERS and L-band JERS radar interferometry. Canadian Journal of Remote Sensing, 31, 7-20.

Lu, Z., et al., 2005c. C-band radar observes water-level change in swamp forests. Eos, Transactions of the American Geophysical Union, 86, 141-144.

Lu, Z., Kwoun, O., and Rykhus, R., 2007a. Interferometric synthetic aperture radar (InSAR): its past, present and future. Photogrammetric Engineering \& Remote Sensing, 73, 217-221.

Lu, Z., et al., 2007b. Diverse deformation patterns of Aleutian volcanoes from satellite interferometric synthetic aperture radar (InSAR). In: J. Eichelberger, et al., eds. Volcanism and subduction: the Kamchatka region, American Geophysical Union Geophysical Monograph Series, 172, 249-261. 
Massonnet, D., et al., 1993. The displacement field of the Landers earthquake mapped by radar interferometry. Nature, 364, 138-142.

Massonnet, D. and Feigl, K., 1998. Radar interferometry and its application to changes in the Earth's surface. Reviews of Geophysics, 36, 441-500.

Masterlark, T. and Lu, Z., 2004. Transient volcano deformation sources imaged with InSAR: application to Seguam island. Journal of Geophysical Research, 109, B01401, Doi: 10.1029/2003JB002568.

Ramsey, E., III, et al., 2006. Multiple baseline radar interferometry applied to coastal landscape classification and changes. GIScience and Remote Sensing, 43, 283-309.

Ramsey, E., et al., 2009. Satellite optical and radar data used to track wetland forest impact and short-term recovery from Hurricane Katrina. Wetlands, 29 (1), 66-79.

Rignot, E. and Thomas, R., 2002. Mass balance of Polar Ice Sheets. Science, 297, 1502-1506.
Rykhus, R. and Lu, Z., 2007. Hurricane Katrina flooding and possible oil slicks mapped with satellite imagery. In: Science and the storms - the USGS response to the hurricanes of 2005. USGS Circular 1306, 50-53.

Touzi, R., et al., 2004. A review of polarimetry in the context of synthetic aperture radar: concepts and information extraction. Canadian Journal of Remote Sensing, 30, 380-407.

Wright, T., 2002. Remote monitoring of the earthquake cycle using satellite radar interferometry. Philosophical Transactions of the Royal Society of London, 360, 2873-2888.

Zebker, H., Rosen, P., and Hensley, S., 1997. Atmospheric effects in interferometric synthetic aperture radar surface deformation and topographic maps. Journal of Geophysical Research, 102, $7547-7563$.

Zebker, H. and Villasenor, J., 1992. Decorrelation in interferometric radar echoes. IEEE Transactions on Geoscience and Remote Sensing, 30, 950-959. 